\title{
A participação docente e colegiada no processo de construção e implementação do currículo de tempo integral.
}

\section{(Teaching and collegial participation in the process of construction and implementation of the full-time curriculum.)}

\author{
Anabela Cardoso Freitas \\ (SEMEC)Teresina-Piauí e da (SEEDUC) do Maranhão.
}

Fecha recepción: 01-10-2017

Páginas 31-45

Fecha aceptación: 01-12-2017

\section{Resumo.}

O trabalho do mestrado fez uma reflexão sobre a participação docente e colegiada no processo de construção e implementação do currículo de tempo integral. A abordagem teve 0 enfoque quantitativo do tipo descritivo, os resultados apontaram que os docentes da fase de construção do currículo da escola de tempo integral tiveram uma formação mais consistente sobre currículo. Nas instâncias colegiadas (conselhos escolares) mesmo com parte de representantes cientes do seu papel, destacou-se algumas discussões sobre currículo e a sistemática de avaliação, prevalecendo a função financeira e disciplinar nos contextos de atuação. Contudo, pouco se discute nos processos decisórios em relação à parte diversificada do currículo ou discussões dos grandes temas curriculares da atualidade na escola para ampliar o diálogo sociocultural para uma educação alternativa.

Palavras-chave: escola integral; currículo; escola; comunidade; formação

\section{Abstract.}

The work of the master's degree focused on the participation of teachers and collegiate in the process of construction and implementation of the full-time curriculum. The approach had a quantitative approach of the descriptive type, the results pointed out that the teachers of the construction phase of the full-time school curriculum had a more consistent formation on curriculum. In collegiate bodies (school councils) even with representatives of their role, some discussions about curriculum and evaluation systematics were highlighted, with a prevailing financial and disciplinary function in the contexts of action. However, there is little discussion in the decision-making process regarding the diversified part of the curriculum or discussions of the major curricular themes of the present time in the school to extend the socio-cultural dialogue to an alternative education.

Keywords: comprehensive school; curriculum; school; community; formation 


\section{1.-Introdução.}

Como política educacional inovadora, a implementação das escolas de tempo integral propõe uma nova forma de atendimento, pois com a ampliação da jornada escolar pretende-se a diversificação das oportunidades para o desenvolvimento pleno dos alunos. Essa intenção está atrelada a uma proposta curricular dentro de uma vertente holística, que vê o sujeito na sua relação intrínseca com o todo, com a natureza e a sociedade, sendo parte integrante, a soma do corpo, mente e alma. Nessa visão a formação integral abrange, além da parte formal e da parte diversificada, metodologias propositivas que vão de encontro às necessidades sociais, interacionais, emocionais, bem como as necessidades ligadas a comunidade, a cidadania plena.

Especificamente na rede pública estadual do Piauí essa modalidade de ensino em tempo integral foi instituída após a publicação das Diretrizes Curriculares Nacionais para o Ensino Médio (em 2008), onde o Governo do Estado planejou os Centros de Educação de Tempo Integral visando à implementação de um modelo educacional que ampliasse o tempo escolar e as oportunidades de aprendizagem dos alunos, de acordo com as metas do Plano Nacional de Educação, que prevê a expansão da jornada ampliada em tempo integral em 50\% das escolas até 2024. A ampliação da jornada é que fundamenta a ideia da escola de tempo integral.

Nesse contexto, as demandas sociais oriundas da "sociedade do conhecimento" geram grandes responsabilidades para o espaço-escola, espaço social e, por outro lado a sociedade civil que, atualmente se apresenta como um espaço de múltiplas oportunidades de aprendizagem.

A pesquisa levou-nos a questionar: Qual seria a forma de organização curricular, formação continuada de uma ETI dentro de uma realidade social multifacetada e em transformação. Como seria o ensino nesta escola de educação integral? O sistema a institucionaliza como uma escola que observa as práticas culturais, a relação escolacomunidade? Tendo em vista o desenvolvimento de uma proposta curricular integrada, conforme os princípios da igualdade, da integralidade, liberdade e nos ideais de solidariedade humana, como é feito o trabalho educativo atrelado à responsabilidade social para construção da mudança rumo a uma cidadania plena? Foram estes os questionamentos que perpassaram essa pesquisa educacional.

\section{2.-Currículo Híbrido.}

As discussões sobre tempo integral na atualidade nos remetem ao estudo sobre hibridismo e currículo, as interlocuções sobre cultura, conhecimento e poder, pósmodernidade e globalização, bem como as práticas multiculturais. 0 currículo híbrido é aquele que busca possibilidades para uma construção de políticas e práticas voltadas para a mudança social, no espaço multifacetado e representativo do todo social, que é a escola. Para Lopes (2005) o hibridismo no currículo está atrelado ao conceito de recontextualizacão (movimento que modifica as dimensões regulatórias, instrucionais e pedagógicas, por exemplo), a desterritorialização, 0 
descolecionamento discussões do campo cultural e ideológico numa diversidade de cenários econômicos, políticos, ideológicos, sociais, estéticos nesse mundo transcultural e midiático. Esse modelo curricular tem uma vertente política porque essas zonas de contato, as formas de intervenção incluem jogos de poder, diversificação de cenários, quadro de necessidades individuais e coletivas, pautas de negociação entre a escola e representações legítimas da comunidade. Discutindo sobre o tema Canclini (1998), enfatiza a vida urbana em seu movimento social rumo à mudança, muitas vezes na contramão das formas regulatórias de controle social $\mathrm{e}$ da visão compartimentada do sistema social.

\section{1.-Discutindo currículo e suas vertentes.}

A discussão sobre currículo independente de sob qual perspectiva de abordagem se consubstancia nos estudos da Sociologia do Currículo, da Epistemologia Social e da História Cultural e Social. Na modalidade de tempo integral a abordagem pressupõe uma multiplicidade de conceitos, tendências e sentidos que não podem ser separados porque estudar currículo pressupõe adentrar-se em conceitos sobre cultura e poder. Em Lopes \& Macedo (2002) ao enfatizarem os diversos enfoques e vertentes estudadas no currículo ressaltam que "tal multiplicidade não vem se configurando apenas como diferentes tendências e orientações teóricometodológicas, mas como tendências e orientações que se inter-relacionam produzindo hibridos culturais". (Lopes; Macedo, 2002, p. 16).

As pesquisas atuais evidenciam que as noções de "história", de "currículo" e de "poder" foram colocadas em destaque, abertas ao diálogo porque a modernidade produz permanentemente interfaces entre estes conceitos e, então, são produzidas novas formas de regulação e estruturação curricular, recontextualizadas e hibridizadas, circulantes que, no Brasil produzem novos híbridos culturais. Refletindo sobre o tema em debate, no enfoque regulatório temos Goodson (1995) numa visão sistêmica que conceitua currículo, junto com a formulação "metas e objetivos', conjuntos, roteiros que, por assim dizer, constitui as normas, regulamentos e princípios que orientam o que deve ser lecionado" (Goodson, 1995, p. 117).

E de como se constituíram enquanto disciplinas, a primeira hipótese, o conceito é 0 de "disciplinas como entidades monolíticas, mutáveis", compostas de vários elementos e de tradições que podem gerar contradições e ao mesmo tempo compromisso, bem como influenciar o caminho da mudança, a segunda hipótese as disciplinas se constituem a partir dos objetivos pedagógicos e utilitários, diretamente ligados aos aspectos práticos e emergentes da realidade, a terceira hipótese os estudos históricos revelam uma constante mudança das disciplinas; que saem de um status marginal e inferior do currículo, passam para o estágio utilitário e, por fim se transformam em disciplina (um conjunto determinado e rigoroso de conhecimentos).

Paraiso (2004) faz uma reflexão da realidade mundo que aponta a necessidade da instituição escolar se adequar ao novo modelo econômico vigente nessa pósmodernidade. No Brasil está em processo a discussão sobre a realidade educacional. Ainda, diz que "as pesquisas pós-críticas no Brasil têm contribuído para 
a conexão de campos, para 0 desbloqueio de conteúdo, para a proliferação de formas e para o contágio de "saberes minoritários".

Assim, a mudança é necessária nesta crise do paradigma científico moderno, onde a evolução do pensamento humano é marcada pela renovação de paradigmas um sobressaindo sobre outro numa sucessão. Behens (2005) refere-se criticamente sobre a crise paradigmática e seus reflexos para a educação, antes reprodutora e conservadora, para a disseminação de outras três abordagens pedagógicas, dentro de uma vertente de "produção de conhecimento". Paradigma da Complexidade coerente com a prática educativa, voltado para a visão de mundo em sua inteireza com paradigmas inovadores: abordagem holística, a progressista e o ensino com pesquisa. (Behens, 2005, p.56).

Assim, o espaço híbrido torna-se um espaço de articulação de culturas diferentes, que permite por sua ambivalência e originalidade, uma nova construção de sentidos. Corroborando nessa visão Alba (2002) sintetiza que os elementos culturais, conforme a proposta curricular, se incorporam não somente através de aspectos formaisestruturais, mas, também, por meio das relações sociais cotidianas (originárias), das quais 0 currículo se desprende para uma prática concreta. (Alba, 2002, p.) Frente às demandas socioculturais que fazem parte das mudanças proporcionadas pelo processo de globalização temos que levantar um ponto de reflexão com o seguinte problema: Qual é o nível de participação docente e colegiada no processo de construção e implementação do currículo em uma ETI, na rede pública estadual de ensino, em Teresina/ Piauí?

\section{2.-Construção (Preparação) do Currículo de Tempo Integral.}

Uma construção possível a partir de uma cultura de massa, da comunidade, Canclini (1998) afirma "o surgimento do hibridismo a partir da criatividade individual e coletiva, sendo capaz de superar hierarquias". Essas são produto das opressões póscoloniais, das zonas de tensão advindas da relação entre cultura e política. Contudo - autor explica que mesmo tensas essas relações geram um processo de negociação- que é onde se origina as políticas de currículo. A realidade é uma afirmação de "discursos, narrativas e saberes. (...) alternativas, que contassem outras histórias". Histórias que, por serem 'alternativas', minassem a inevitabilidade e a 'naturalidade' das narrativas dominantes.

No entanto, o Currículo de Tempo Integral, surge como aporte teórico-metodológico, nessa compreensão a educação de tempo integral se fundamentará em diversas concepções e vertentes epistemológicas que perpassam primeiramente pela ideia da Paidea grega, do homem integral, com formação clássica, mas também com formação para as artes, como a música e o conhecimento das matérias clássicas como a filosofia, até chegar ao apogeu do liberalismo, As tendências se efetivam institucionalmente através dos temas curriculares implementados. Na proposta de "formação integral do homem", na escola de vertente capitalista, se retorna a idéia de educação integral, para atender as demandas do mercado pela mão de obra feminina, em plena ascensão, no final do século XIX até meados do século XX. 
Após os "modismos na educação", na década de 80, o Brasil assiste a "saraivada" de correntes e teorias pedagógicas que vão rechear o trabalho pedagógico escolar com ideias e concepções, e sobreposição de vários modelos pedagógicos. Com a passagem da modernidade para a pós-modernidade temos a influência dos teóricos sócio críticos, críticos e pós-críticos que vêm à educação no contexto da globalização, no seu processo histórico, real. A escola atual e o currículo de tempo integral pode realizar a síntese de ideias que referendam a educação atualmente no Brasil os modelos de educação integral.

\section{3.-Representação Colegiada e Mudança Sociocultural.}

O currículo, perpassa por uma perspectiva de escolarização, tendo uma tendência muito forte de uma "visão internalista", que, de acordo com Dole (2009), muitas vezes, os estudos não enfocam as questões ou "efeitos externos que imbricam" com as forças curriculares internas na sua função regulatória. 0 autor se posiciona criticamente sobre "essas variáveis" advindas do contexto e afirma que "[...] Estamos interessados em como fatores externos não somente 'afetam' mas 'constroem' o pensamento e a prática curricular no contexto das prioridades e dos sistemas educacionais, os quais estão sendo transformados pela globalização" (Dole, 2009, p. 18).

Contudo, somos afetados dentro da escola pela presença de mecanismos regulatórios e de controle social (horário, regimento, disciplina, folha de ponto, frequência, notas classificatórias e muitos outros); temos dentro dos contextos educacionais as condições para a construção e a (des) construção de pensamentos e paradigmas ultrapassados, bem como, mudanças no currículo, fruto dessas conexões oriundas das redes de significados socioculturais.

\section{3.-Metodologia.}

Neste estudo "a participação docente e colegiada no processo de construção do currículo de tempo integral, na rede pública de ensino, em Teresina, Piaui", em 2016 partiu de um levantamento bibliográfico, revisão da literatura, dos estudos já realizados por diversos teóricos, a fim de escolha do melhor método e do instrumental para recolhimento de dados e delineamento correto. Sobre 0 assunto Richardson (1989, p. 29), ressalta que "[...] método em pesquisa significa a escolha de procedimentos sistemáticos para a descrição e explicação de fenômenos". A abordagem quantitativa, para a descrição do resultado apontado pelo instrumento aplicado, bem como, pela execução de uma análise dos dados do questionário aplicado.

A pesquisa se utilizou do enfoque quantitativo do tipo descritivo, de forma transversal, transseccional, por amostragem estratificada, selecionada em cinco (05) escolas de tempo integral (ETI): duas Escolas de Ensino Fundamental (CETI) e duas (02) Escolas de Ensino Médio (CEMTI) e uma de ensino médio integrado e ensino profissional (CEMPTI). A pesquisa foi de desenho não experimental porque não houve manipulação de variáveis, com procedimentos e amostragem estratificada, 
transeccional, transversal, sincrônico, escolha aleatória, com a composição dos dados feita através de análises quantitativas, seguidas de descrição das respostas sobre a situação estudada.

A população foi de 137 docentes das ETI da Rede Pública Estadual da cidade de Teresina, engajamento social, acerca do protagonismo necessário que seja estabelecido nessa relação escola-comunidade. A amostragem: $30 \%$ das ETI; 30\% das ETI e as unidades de Análise foram: cada um dos 54 docentes; cada um dos 54 representantes dos colegiados, dos cinco (05) centros estaduais de tempo integral (CETI), da rede pública estadual de ensino. Amostra cumpriu o nível de exigência de $95 \%$, com margem de erro de $6 \%$; onde a amostragem foi estratificada. A amostra foi composta de $40 \%$ professores (por escola) e $40 \%$ dos representantes dos colegiados por escola.

\section{4.-Discussões dos resultados.}

A pesquisa nessa perspectiva fomentou discussões, debates, bem como, fazeres, dizeres, saberes (daqueles que fazem a educação acontecer- os professores); que vão sendo acionados pela necessidade das práticas culturais e trocas educacionais. Essas trocas culturais e sociais ocorrem no ambiente da escolarização, facilitando a passagem de um currículo somente regulatório para um "outro" mais conectado, mais identificado com as necessidades dos alunos.

A pesquisa ocorreu com o uso de (02) questionários: (01), com questões fechadas, do tipo policotômico, outro com questões em formulário B, perguntas semiestruturadas (com a participação de professores), e outro questionário dicotômico e com algumas questões semiestruturadas para representantes dos colegiados $(40 \%)$, selecionados por amostragem estratificada, respeitando as duas dimensões elencadas na pesquisa.

As perguntas do questionário $A$, de enfoque quantitativo foram diretas, semiestruturada, e do formulário B (do tipo dicotômico), foram fechadas para compor os instrumentos de coleta de dados junto aos docentes. $\mathrm{O}$ questionário $\mathrm{C}$ foi composto de perguntas, dicotômico, com algumas questões semi-estructurada, aplicado aos representantes dos colegiados escolares. A ferramenta tecnológica utilizada para análise de dados foi SSPS, versão 17.0, do ano 2010. Excell do Windows versão 2010.

a). Realidade e interfaces entre a escola de tempo integral e a comunidade escolar. O funcionamento dos colegiados escolares é uma instância muito importante para a escola de tempo integral, e segundo Canclini (1998) pode fomentar "associações entre 0 culto e o popular, entre estratos culturais de classes sócias distintas, entre outros", para dentro da escola. Ou seja, colaborar com a transformação da cultura política em cultura pedagógica e vice-versa.

b). Análises dos dados levantados pelo formulário B, para docentes da ETI com as dimensões da pesquisa. 
1). Informações sobre a preparação para o currículo de tempo integral.

Na preparação para o trabalho com o currículo de tempo integral, as análises dos dados revelaram que $67 \%$ dos docentes não têm conhecimento algum sobre educação integral e escola de tempo integral. 0 percentual de $33 \%$ dos docentes que responderam que tinham informações sobre 0 assunto são aqueles oriundos das primeiras escolas de tempo integral (2009).

A análise volta-se para as transformações da formação continuada, de forma que os docentes das escolas da primeira fase (de 2009 a 2012) tiveram orientações e acompanhamento mais sistemático. A partir de 2013 a 2016 o eixo da formação volta-se para sistemática de avaliação e estudos sobre processos de avaliação externa e da rede pública estadual, como 0 SAEPI- Sistemática de Avaliação em Educação do Estado do Piauí.

Gráfico 1: Informações sobre Educação e Escola de Tempo Integral.

\section{Tem sido informado(a) sobre educação e escola de tempo integral?}

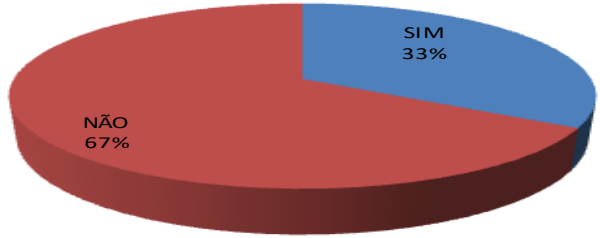

Fonte: A própria pesquisa direta (2017).

Sobre currículo na perspectiva de ensino de tempo integral, $72 \%$ nunca tiveram informação sobre currículo e $28 \%$ dos docentes já participaram de uma formação continuada sobre currículo. Os dados evidenciam que a própria estrutura das matrizes curriculares para o ensino fundamental e ensino médio, são pouco divulgadas e as respostas mostraram a fragilidade do preparo docente para atuar nessa modalidade de ensino. Vejam o gráfico:

Gráfico 2: Formação continuada sobre currículo no ensino em tempo integral.

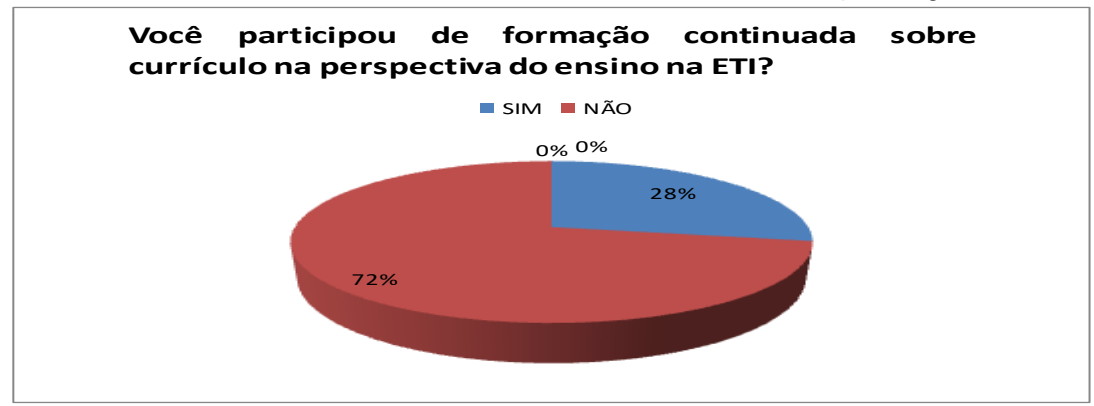

Fonte: A própria pesquisa direta (2017). 
2). Informações sobre formação docente continuada.

$\mathrm{Na}$ dimensão 'formação docente continuada' os professores revelaram que $52 \%$ participam das formações 'genéricas' da rede pública estadual de ensino e 48\% não participam dessas formações. Essa informação é mais geral porque a pergunta é relacionada "a qualquer tipo de formação", analisada na perspectiva de encontro de socialização entre os pares. Atualmente (2016/2017) praticamente à metade dos professores participaram das formações do Pacto Nacional pelo Fortalecimento do Ensino Médio (PFNEM) e das formações do "chão da escola".

Gráfico 3: Participação em formação continuada na Rede Pública Estadual

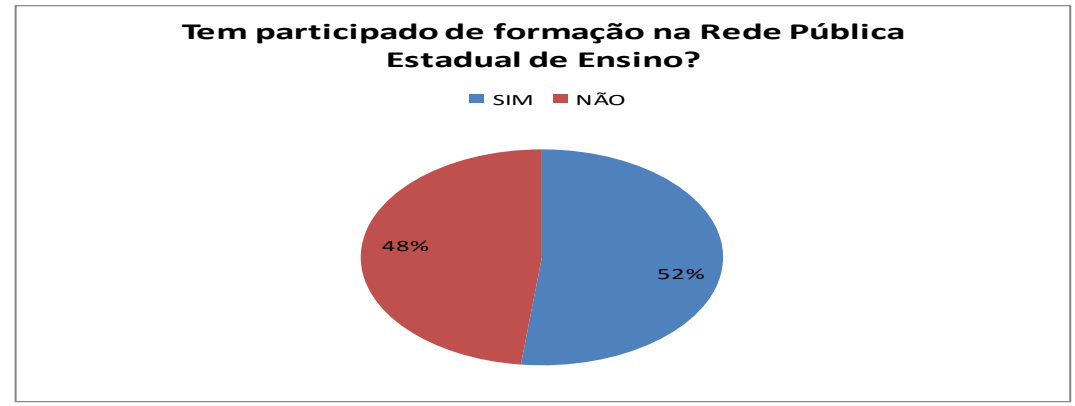

Fonte: A própria pesquisa direta (2017).

No item sobre modelos de formação docente, para $70 \%$ dos pesquisados os modelos atuais não atendem as necessidades de um professor que atua numa escola de tempo integral. A pesquisa revela que tanto a formação docente quanto a formação continuada não atendem às necessidades oriundas da prática pedagógica dos professores.

Gráfico 4: Modelos de formação e o atendimento à necessidade do professor

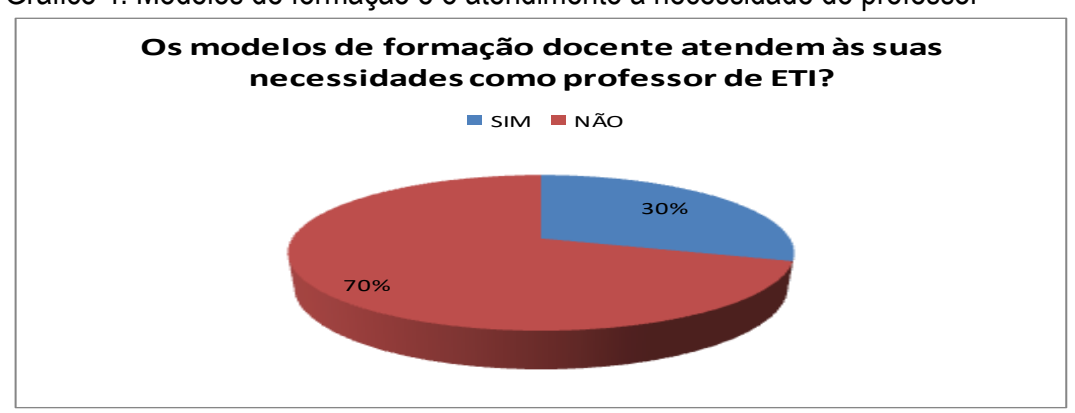

Fonte: A própria pesquisa direta (2017).

3). Informações sobre implementação do currículo de tempo integral.

Em relação ao item sobre "o conceito de educação holística" conceito ligado à ideia de formação integral do aluno, $63 \%$ dos docentes marcaram que não compreendiam o conceito de educação holística. 
Gráfico 5: Conceito de Educação Holística

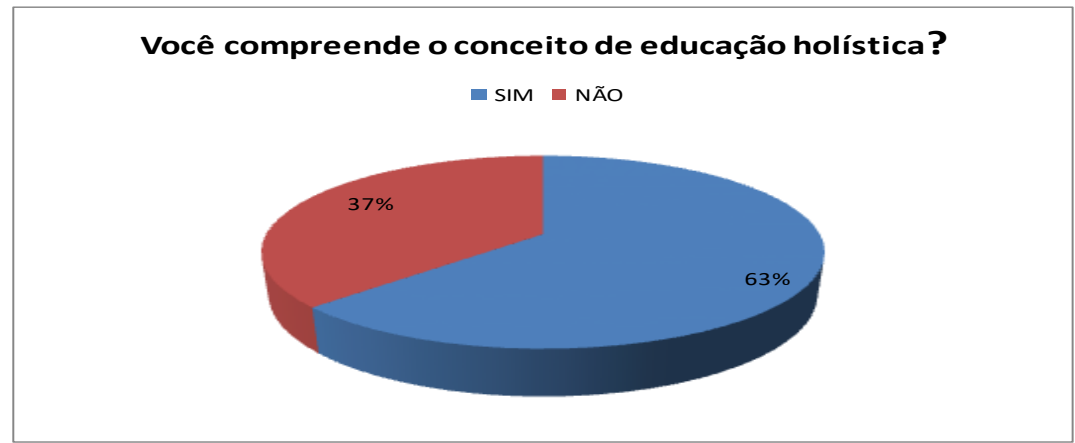

Fonte: A própria pesquisa direta (2017).

Especificamente sobre o currículo atual das escolas de tempo integral, da rede pública estadual de ensino, da cidade de Teresina, capital do estado do Piauí, no item "c" os $61 \%$ dos docentes marcaram que o currículo atual não atende a formação integral do aluno, 39\% marcaram que o modelo de currículo atende para a formação integral dos alunos. Para os docentes das ETI, o currículo não atende, não promove a formação integral do aluno porque "fazer um trabalho diferenciado" é uma ideia do que deve ser o tempo integral.

Gráfico 6: 0 currículo de uma ETI e a formação integral do aluno

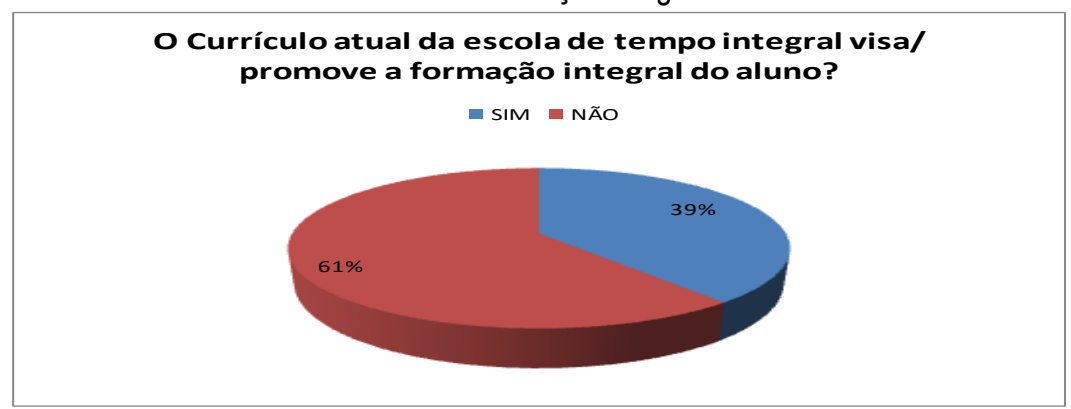

Fonte: A própria pesquisa direta (2017).

Nesse item "d" sobre hibridismo somente $11 \%$ dos professores marcaram e demonstraram terem algum conhecimento sobre hibridismo e currículo numa perspectiva de escola de tempo integral, de mudança sociocultural. Entre os docentes, $89 \%$ declararam "nunca ouviram falar desse conceito". Ocorre que os $11 \%$ que demonstraram compreensão sobre esse conceito tornaram evidente que esse conhecimento veio da formação inicial, quando do início do Programa das Escolas de Tempo Integral (em 2009), da qualificação com os consultores do Instituto Corresponsabilidade, do Estado de Pernambuco. Os outros $89 \%$ são souberam estabelecer conexões entre currículo oficial, currículo real-vivido ou o alternativo. 
Gráfico 7: Conceito de hibridismo e currículo de uma ETI.

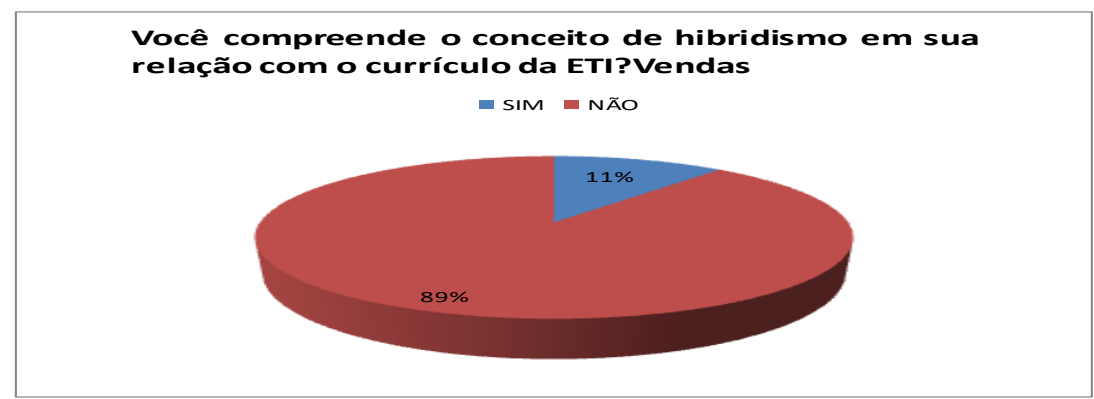

Fonte: A própria pesquisa direta (2017).

4). Informações sobre representação colegiada e mudança sociocultural.

Nesse dado "Informações sobre Representação Colegiada e Mudança Sociocultural", sobre à atuação dos colegiados escolares, como instância representativa da "voz da comunidade", $11 \%$ discordaram e, $89 \%$ dos docentes concordaram que esses colegiados fomentam a relação escola-comunidade.

Gráfico 8: Colegiados da ETI em sua relação com a escola-comunidade.

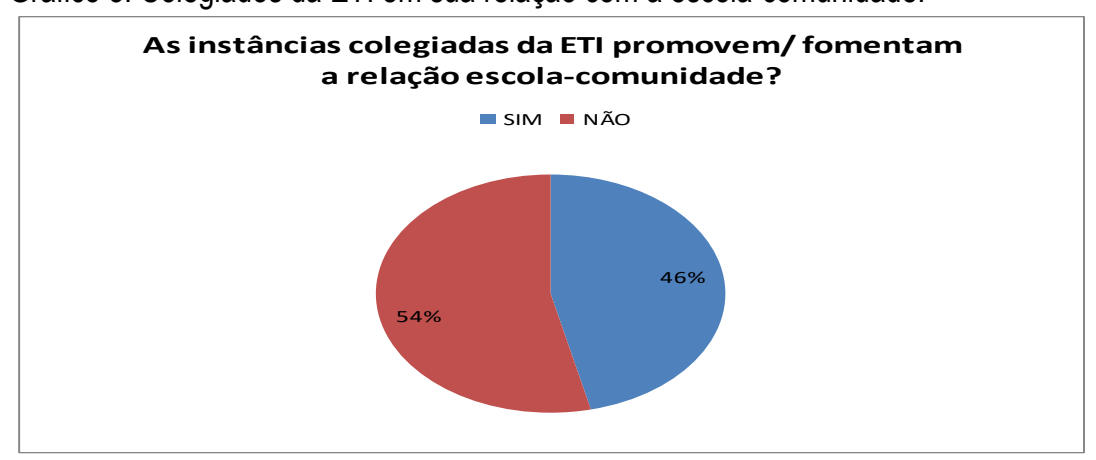

Fonte: A própria pesquisa direta (2017).

Nesse item sobre parcerias entre a escola e a comunidade a resposta dos docentes aproxima-se e responde as interlocuções que enriquecem a pesquisa. Isso porque $44 \%$ dos docentes marcaram que a escola de tempo integral não tem estabelecido conexões e parcerias com a comunidade para trocas culturais e educacionais. Enquanto $56 \%$ dos entrevistados declararam que há essas parcerias.

5). A relação escola-comunidade.

Gráfico 9: A ETI e tipos de contato, convergência, relacionamento, parcerias com a comunidade. 


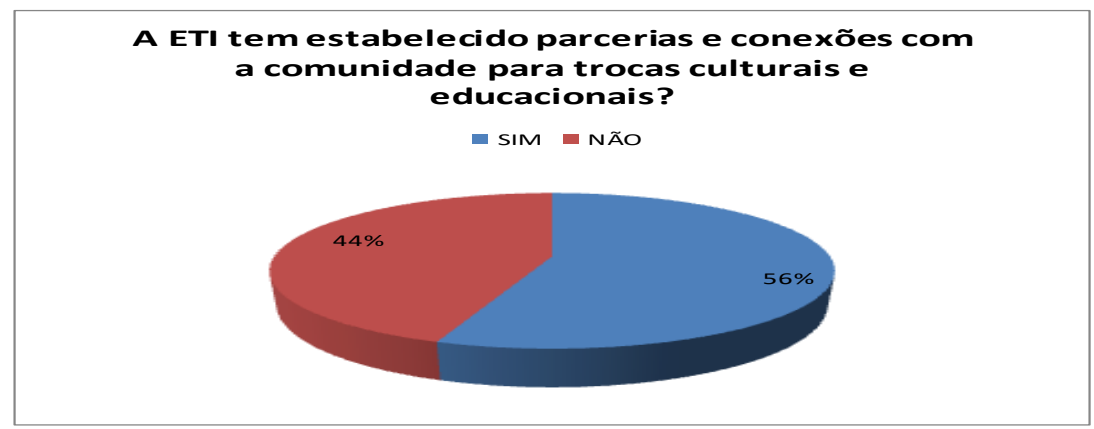

Fonte: A própria pesquisa direta (2017).

Especificamente no item que diz respeito às trocas culturais e educativas entre a escola e a comunidade, $93 \%$ dos professores assinalaram que a escola não instalou nenhum projeto pedagógico e/ ou disciplina atendendo pedido da comunidade. A falta de acesso da comunidade para participar de processos decisórios e deliberativos tem relação com o modelo de tempo integral instalado na rede estadual de ensino, onde prevalece uma composição entre o modelo autoritário e o modelo assistencialista.

Gráfico 10: A ETI e a instalação de projeto pedagógico e/ ou disciplina da grade curricular.

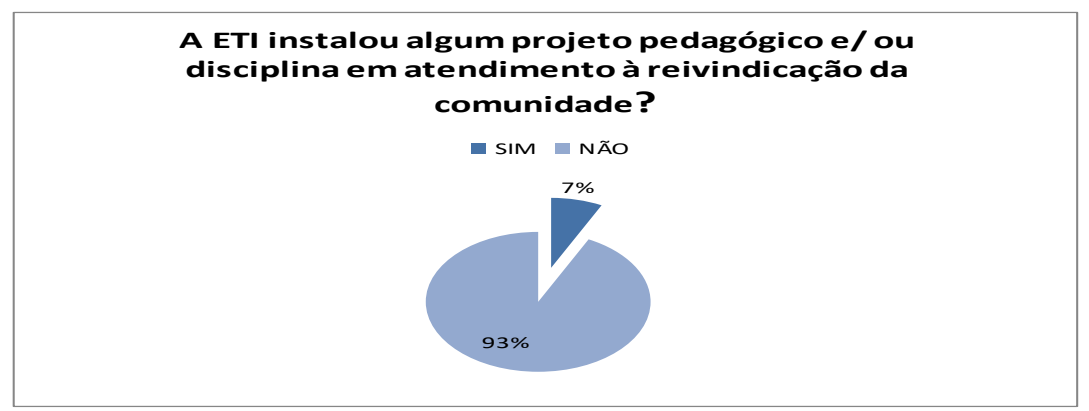

Fonte: A própria pesquisa direta (2017).

c). Análises do questionário c aplicado com membros dos colegiados escolares.

Durante a pesquisa nas escolas pertencentes a amostra, vimos quão pouca é a variedade de assuntos, ações ou reivindicações que conseguem "ultrapassar" a barreira da "oficialidade" da existência ou da função, essencialmente burocrática e administrativo-financeira dos conselheiros. "As questões pedagógicas" quando existem são marcadas pela função regulatória, regimental ou funcional da escola.

Questionário: Representantes dos colegiados escolares Informações sobre.

Os colegiados escolares preparam os indivíduos para atuarem como representantes da sociedade civil. (Gohn, 2006, p. 33). Nessa pesquisa um dado importante foi 0 aparecimento de discussões sobre a sistemática de avaliação e currículo e 'demandas e pedidos da comunidade'. Os dados mostram uma evolução das escolas 
rumo a uma gestão democrática, mas, ainda com a função regulatória, regimental muito presentes nessas participações da comunidade.

Gráfico 11: Temas discutidos nas reuniões colegiadas
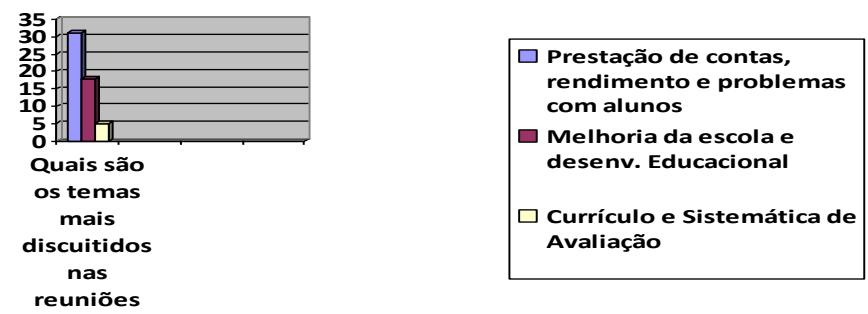

Fonte: A própria pesquisa direta (2017).

Gráfico 12: Temas "mais" discutidos nas reuniões colegiadas

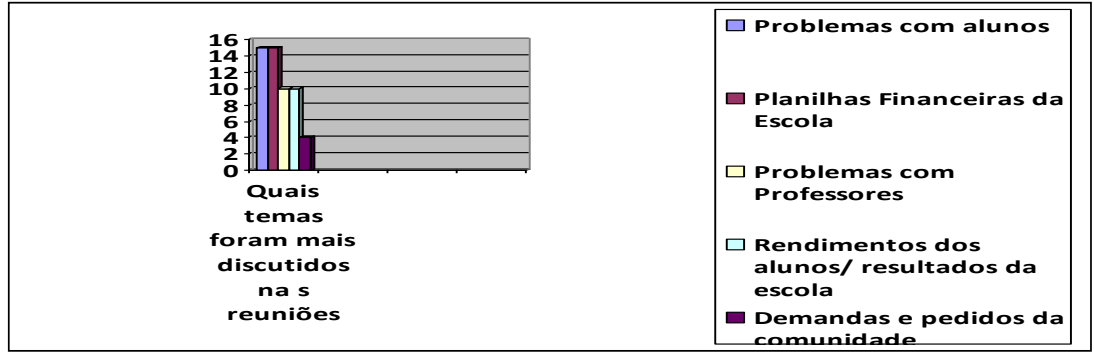

Fonte: A própria pesquisa direta (2017).

No item sobre disciplina implementada à pedido da comunidade; $92,6 \%$ informaram que "não" teve nenhuma disciplina implementada a pedido da comunidade, e apenas $7,4 \%$ informaram que participaram de discussões sobre disciplinas a serem implementadas a pedido da comunidade. Somente na implantação (2009) dos Centros Estaduais de Tempo Integral, houve reuniões de sensibilização, onde a comunidade representada pelos conselheiros foi ouvida na escolha das disciplinas da parte diversificada do currículo.

Gráfico 13: Disciplina implementada a pedido da comunidade.

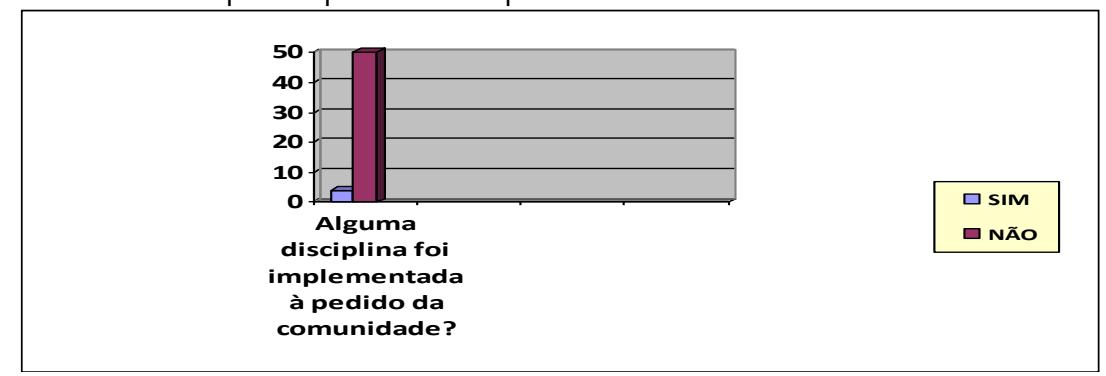

Fonte: A própria pesquisa direta (2017). 


\section{4.-Conclusão.}

Para definição da pesquisa aplicada quanto "Escola de Tempo Integral: buscou-se a participação e colegiada no processo de construção e implementação do currículo na rede púbica estadual de ensino, na cidade de Teresina, estado do Piauí", em 2016. Pelo estudo pode-se inferir respostas, a partir da interpretação dos resultados ou da dissonância em algumas respostas, evidenciando reuniões de sensibilização da qual a comunidade representada pelos conselheiros na escolha das disciplinas bem como da parte diversificada do currículo.

Assim sendo, o objetivo principal "descreveu o nível de participação docente e colegiada na construção e implementação do currículo de Tempo Integral na rede pública estadual de ensino, em Teresina-Piauí, especificamente sobre os seguintes objetivos específicos que:

a) Verificou o desenvolvimento, fase de preparação para a construção do currículo de tempo integral;

b) Verificou a implementação do currículo de tempo integral;

c) Descreveu a qualidade da representação dos órgãos colegiados da escola de tempo integral;

d) identificou a formação docente para a efetivação do currículo de tempo integral;

e) Verificou as formas de relacionamento entre a escola-comunidade.

Deste modo, as formas de participação docente e colegiada na construção e implementação sobre currículo estão relacionadas aos conceitos e definições sobre 0 currículo formal e institucionalizado. As formas mais atualizadas de construção curricular, o estudo de grandes temas curriculares da atualidade como culturas híbridas, gêneros híbridos, intertransculturalidade, multiculturalismo ainda não fazem parte da agenda de formação dos docentes em tempo integral.

Pode-se dizer que, a perspectiva vislumbra mudança sociocultural para a comunidade, tendo a congruência da relação escola-comunidade, e da rede de compartilhamento e de trocas culturais através de ações dos conselhos e colegiados escolares. Ocorre que mesmo sentindo as mudanças e as necessidades de fazer essa ponte entre a escola e a comunidade, a prática docente fica sempre atrelada a função regimental e instrucional do ensino.

Ainda, a formação continuada necessariamente pode dar suporte aos docentes para discussões e reflexões sobre essas temáticas que diz respeito ao currículo, hibridismo e escola de tempo integral. No entanto, evidenciou-se que a concepção assistencialista e autoritária ainda está presente nas escolas de tempo integral da rede pública estadual do Estado do Piauí. Contudo já se verifica uma abertura entre os professores e membros dos colegiados, pois os resultados das informações coletadas dão conta de que os pesquisados consideram que o tempo integral deve ser um ensino "diferenciado", uma educação 'especial'.

No aspecto teórico e do ensino, na Escola de Tempo Integral no Brasil prevalece uma mescla do modelo autoritário e do assistencialista, onde não há um grande espaço 
que levem a uma reflexão sobre os grandes temas curriculares originados localmente. Nesse sentido, as zonas de contato entre o "mundo da escola", local do currículo formal, regulatório, de função instrucional e o "mundo global", local do currículo híbrido e multicultural, não proporciona um verdadeiro canal de diálogo sobre o que o indivíduo, o aluno, mas, que também, é representante desse lócus cultural, quer dizer o precisa da escola e o que a escola pode fazer por ele.

$\mathrm{Na}$ relação escola-comunidade a pesquisa são discutidas e deliberadas através desses conselhos escolares e a pouca variedade de assuntos, ações ou reivindicações que conseguem "ultrapassar" a barreira da "oficialidade" da existência ou da função, essencialmente burocrática e administrativo-financeira dos conselheiros. "As questões pedagógicas" quando existem são marcadas pela função regulatória, regimental ou funcional da escola. Os membros dos colegiados tem suas prerrogativas cerceadas pelo modelo autoritário e regulatório existente no contexto escolar, bem como pelo paradigma da sua formação, que o faz funcionar na prática igual a uma "peça da engrenagem", em detrimento das reivindicações e da escola funcionar como "usina de ideias", com o conhecimento e os saberes escolares numa ótica nova mundial e alternativa, dentro do conceito de "mundo educador" (Gadotti, 2006).

No entanto, os atores sociais na própria escola estão em constante conflito com sua visão, seus valores, sua formação, com o próprio sistema de ensino. Entendemos que esse mesmo 'palco', que é a escola formal, de educação pública, também é espaço de luta e de convergência de processos multiculturais que podem mudar a concepção e o modo de se fazer a prática pedagógica de tempo integral. Para 0 acesso institucional necessita dos atores sociais comprometidos, que queiram romper com o "antigo" para dar uma nova roupagem à sua prática, com novos paradigmas, rumo a uma intertransculturalidade.

Contudo, é emergencial dotar-se de escolas de tempo integral, com estrutura básica, que dê acesso ao aluno se interconectar com o mundo da informação que pode se transformar no "mundo educador", tudo dentro de uma ótica global. Essa prática de fazer ensino alternativo precisa-se de docentes que estejam aptos a novos horizontes que auxilie os alunos aos novos conhecimentos, tanto de forma individual quanto social. Esse propósito social, cultural, pode-se considerar político ao direcionar a tomada de decisão tanto para os docentes quanto para os alunos, como futuros protagonistas de suas próprias histórias.

\section{6.-Referências.}

Alba, A. (2002). Currículum: Crisis, Mito y perspectivas. Santa Fé, Bogotá: Miño y Dávila Editores.

Behrens, M.A. (2005). Aprender a Aprender. Formação Continuada dos professores e a prática pedagógica. Curitiba, Paraná: Champagnat.

Canclini, N.G. (1989). Cultura Libre: Estrategias para entrar y salir de la modernidade. San Bartolo Naucalpan, Argentina Poniente: Editorial grijalbo. 
Coelho, C., Coimbra, L.M.C. (2004). História (s) da educação integral (v.21). Porto Alegre, Rio Grande do Sul: Artmed.

Decreto $n^{0} 13.457$ de 18/12/ 2008. (2008). Estabelece o Programa de Tempo Integral na Rede Pública Estadual de Ensino. Teresina, Piauí: SEDUC.

Dole, R. (2009). A Globalização e o Desenho Curricular. Campinas, São Paulo: Alínea.

Floréz, O.R. (1994). Hacia uma Pedagogia del Conocimiento. Santa Fé de Bogotá, Colombia: Mc Graw-Hill.

Fullan, M. (2011). Investigación sobre el cambio educativo: presente y futuro. Madrid: Revista de Investigación v.9, n.18, p. 53-62.

Gadotti, M. (2006). Perspectivas atuais da educação. Porto Alegre, Rio Grande do Sul: Artes Médicas.

Goodson, I.F. (1995). História do currículo, profissionalização e organização social do conhecimento: paradigma para a história da educação. In: Currículo. Teoria e História. Petrópolis: Vozes.

Hobsbawm, E. (1995). Introdução: a invenção das tradições. In: Hobsbawm, E., Ranger, T. (orgs.) A Invenção das Tradições. 3. ed. Rio de Janeiro: Paz e Terra.

Ferreira, M.S., Jaehn, L. (2012). Perspectivas para uma História do Currículo: As contribuições de Goodson, I., Popkewitz, T. Currículo sem fronteiras. Santa Fé de Bogotá, Colombia: Mc Graw-Hill.

Lopes, A.C., Macedo, E. (2002). O pensamento curricular no Brasil. In: Lopes, A.C., Macedo, E. (orgs.) Currículo: debates contemporâneos. São Paulo: Cortez.

Lopes, A.C. (2005). Recontextualização e Hibridismo. Currículo sem fronteiras. São Paulo: Revista educação jul./dez. v.5, n.2, p. 50-64.

Michels, M.H. (2006). Gestão, A formação docente e inclusão: eixos da reforma educacional brasileira que atribuem contornos à organização escolar. São Paulo: Revista Brasileira de Educação. vol.11, n.33, p.406-423.

Paraíso, M.A. (2004). Pesquisas pós-críticas em Educação no Brasil: Esboço de um mapa. Minas Gerais: Cadernos de Pesquisa de maio/agosto: v.34, n.2, p.122.

Popkewitz, T.S. (1997). Reforma educacional: uma política sociológica. Poder e conhecimento em educação. Trad. Beatriz, A.N. Porto Alegre, Rio Grande do Sul: Artes Médicas.

Sacristán, J.G. (2007). 0 currículo: uma reflexão sobre a prática. Porto Alegre, Rio Grande do Sul: Artmed. 